УДК 338

\title{
СТРАТЕГИЧЕСКИЙ АНАЛИЗ И ПУТИ ПОВЫШЕНИЯ КОНКУРЕНТОСПОСОБНОСТИ ПРЕДПРИЯТИЯ
}

\section{Карапетян Лилия Артаковна магистрант \\ Маняева Вера Александровна}

д.э.н., доцент

ФГАОУ ВО «Самарский государственный экономический университет»

\begin{abstract}
Аннотация: В статье рассматриваются особенности проведения и методы стратегического анализа и оценки конкурентоспособности компании. Стратегический анализ проводится на примере компании «Л’Этуаль». Дана общая характеристика компании, стратегический анализ компании и оценка конкурентоспособности. По результатам анализа предложены пути повышения конкурентоспособности предприятия.
\end{abstract}

Ключевые слова: стратегический анализ, SWOT-анализ, PEST-анализ, матрица М. Портера, конкурентоспособность.

\section{STRATEGIC ANALYSIS AND WAYS TO IMPROVE THE COMPETITIVENESS OF THE ENTERPRISE}

\section{Karapetyan Lilia Artakovna Manyaeva Vera Alexandrovna}

\begin{abstract}
The article discusses the features and methods of strategic analysis and evaluation of the competitiveness of the company. The strategic analysis is carried out on the example of the company "L'Etoile". The general characteristics of the company, the strategic analysis of the company and the assessment of competitiveness are given. Based on the results of the analysis, ways to increase the competitiveness of the enterprise are proposed.

Keywords: strategic analysis, SWOT analysis, PEST analysis, M. Porter matrix, competitiveness.
\end{abstract}




\section{МОЛОДЕЖНАЯ НАУКА КАК ФАКТОР И РЕСУРС ИННОВАЦИОННОГО РАЗВИТИЯ}

В рыночных условиях важно быстро адаптироваться к изменяющейся внешней и внутренней среде. Для этого необходимо провести анализ внешней среды, оценить деятельность конкурентов и место на рынке компании. Для этого проводится стратегический анализ, по результатам которого разрабатывается стратегия развития. От того, насколько точно и тщательно проведен стратегический анализ и оценка конкурентоспособности, зависит эффективность выбранной стратегии развития.

Исследованию особенностей проведения стратегического анализа, его методов и этапов посвятили работы Р.И. Акмаева [1], Э.М. Абубакарова и И.У. Шахгираев [2], А.М. Лаптева и И.К. Васькова [3], Л.Н. Чайникова [4] и др.

Большое значение имеет концептуальная и технологическая связь между стратегией и используемыми организационными решениями. Каждая успешная фирма должна иметь бизнес-стратегию развития, понимая, что это очень важно для достижения новых успехов в будущем. Каждая фирма выбирает для себя бизнес-стратегию в зависимости от ситуации, в которой она находится в данный момент.

Отсутствие хорошо разработанной стратегии развития, адаптированной к возможным изменениям факторов внешней среды в современных реалиях ведения бизнеса может привести к тому, что принимаемые решения отдельных структурных подразделений будут носить разноплановый характер, что в свою очередь будет негативно сказываться на эффективности деятельности предприятия в целом.

Стратегический анализ компании и внешней среды состоит из анализа макросреды, микросреды, анализа потребностей и поведения потребителей, анализа внутренней среды. Разделяем точку зрения, чтобы «провести анализ макроокружения используется PEST-анализ, который включает в себя политические, экономические, социальные и технологические факторы. Также есть расширенные виды PEST-анализа, например, PESTLE анализ, который включает в себя также юридические факторы и факторы окружающей среды» [1, c. 99].

Во время проведения PEST-анализа, экспертным методом оценивается влияние каждого фактора макроокружения на деятельность компании.

После того, как проведен анализ макросреды, проводится анализ микросреды, который включает в себя анализ конкуренции. На данном этапе 
необходимо провести анализ своих конкурентов, выделить их плюсы и минусы, используемые стратегии развития и продвижения на рынке. Также на этапе анализа микроокружения оценивается работа с поставщиками, каналы сбыта, целевая аудитория. Для проведения анализа используется конкурентный анализ 5 сил Майкла Портера, который включает анализ влияния конкурентов, товаров-заменителей, контактной аудитории, потребителей, поставщиков на деятельность компании. Также необходимо составить портрет целевого потребителя и описать его поведение.

По результатам проведенного анализа составляется SWOT-анализ, включающий в себя сильные и слабые стороны компании, ее возможности и угрозы. Для анализа внутренней среды могут использоваться и такие методы стратегического анализа, как оценка ресурсов, конкурентных преимуществ, оценка конкурентных позиций, организационная диагностика, Канва бизнесмодели.

Проведем стратегический анализ, используя SWOT-анализ, на примере компании «Л’Этуаль» и, по его результатам, предложим рекомендации по повышению конкурентоспособности компании. «Л’Этуаль» - крупная торговая компания, которая занимается реализацией косметической и парфюмерной продукции по всей России. Магазины компании присутствуют в каждом крупном городе России, а также работает интернет-магазин с возможностью заказать любой товар с доставкой на дом.

Результаты SWOT-анализ представлены в таблице 1.

\section{Таблица 1}

SWOT-анализ «Л’Этуаль»

\begin{tabular}{|l|l|l|}
\hline & \multicolumn{1}{|c|}{ Сильные стороны } & \multicolumn{1}{|c|}{ Слабые стороны } \\
\hline Возможности & Расширение ассортимента магазина & Разработка постоянных акций со \\
& путем добавления серии косметики из \\
& снатуральных компонентов & Упор на онлайн-магазин и \\
& Расширение сети офлайн-магазинов & оперативную доставку \\
& Разработка новых рекламных кампаний \\
& с участием знаменитостей & \\
\hline
\end{tabular}




\section{МОЛОДЕЖНАЯ НАУКА КАК ФАКТОР И РЕСУРС ИННОВАЦИОННОГО РАЗВИТИЯ}

Продолжение таблицы 1

\begin{tabular}{|l|l|l|}
\hline Угрозы & Повышение эффективности работы & Совершенствование \\
& онлайн-магазина и сокращение срока & обслуживания в офлайн- \\
& доставки товара & магазинах \\
& Разработка новых акций и предложений & Увеличение объемов продаж \\
& путем снижения цен \\
\hline
\end{tabular}

Таким образом, подводя итог по анализу внешней и внутренней среды можно сделать выводы:

1. Компания достаточно известна на рынке, занимает лидирующие позиции, имеет свои преимущества и недостатки перед конкурентами.

2. Среди возможностей компании, были выделены: повышение доходов населения; изменение предпочтений покупателей в пользу натуральной косметики; открытие новых магазинов.

Далее приведем анализ конкурентоспособности компании на рынке на основе открытых источников. Аналитики отмечают, что «лидером рынка остается торговая сеть «Магнит Косметик», нарастившая выручку на 22,4\% до 134,3 млрд руб. за год (здесь и далее приведена выручка без НДС). Вторую строку рейтинга сохраняет за собой «Л’Этуаль» с товарооборотом 74,1 млрд руб. и с ощутимой отрицательной динамикой выручки по сравнению с предыдущим календарным периодом - минус 12,17\%. На третьем месте располагается ТД «Улыбка радуги»: 35,2 млрд руб. и 7,88\% роста. В пятерку лидеров рынка входят также маркетплейс Wildberries c товарооборотом 31,4 млрд руб. в категории "Товары для красоты" и ростом продаж на 156\% и сеть «Рив Гош» - 30 млрд руб., минус 19,21\%. В связи с чем, основными конкурентами «Л’Этуаль» являются: «Магнит Косметик», ТД «Улыбка радуги» и «Рив Гош». Wildberries не будем считать прямым конкурентом, т.к. это маркетплейс и у компании нет офлайн-магазинов» [5].

Результаты проведенной оценки конкурентных позиций каждой компании позволили сделать следующие выводы: «Л'Этуаль» занимает лидирующие позиции на рынке и получила практически максимальные оценки по реализации (т.к. имеет широкую фирменную сеть магазинов по всей стране, а также действует интернет-магазин). Наименьшие баллы компания получила по ценовым критериям, т.к. цена на многие товар немного выше, чем аналогичный товар конкурента. 


\section{МОЛОДЕЖНАЯ НАУКА КАК ФАКТОР И РЕСУРС ИННОВАЦИОННОГО РАЗВИТИЯ}

Таким образом, стратегический анализ и оценка конкурентоспособности, показали, что «Л’Этуаль» занимает лидирующие позиции на рынке и проигрывает своему основному конкуренту «Магнит Косметик» в объеме продаж, количеству магазинов и по ценовому сегменту.

В качестве путей повышения конкурентоспособности компании предлагается совершенствовать работу интернет-магазина: сделать более быструю доставку, добавить возможность просмотра наличия товара в конкретном магазине. Наладить более быструю и стабильную работу приложения. Необходимо сконцентрироваться именно на интернет-продажах (но не забывать про офлайн магазины), т.к., как показал 2020 год, компании, которые имели интернет-магазины, смогли сократить падение выручки в результате закрытия магазинов. Сложно предугадать будут ли 2021-2022 годы более стабильными по работе или произойдет еще одна волна пандемии и офлайн магазинам придется закрыться на время. А концентрирование на интернет-продажах позволит компании минимизировать потери от временного закрытия магазинов.

Кроме того, важным направлением в повышении конкурентоспособности является разработка различных акций и предложений. В условиях, когда реальные доходы населения падают, средняя заработная плата замедляет свой рост, важно предложить покупателю ценовое предложение, от которого он не сможет отказаться. Поэтому необходимо мобилизовать все свои ресурсы и сократить расходы компании, чтобы предложить более выгодные цены.

\section{Список литературы}

1. Акмаева, Р.И. Стратегический менеджмент: учебное пособие / Р.И. Акмаева - Москва: Русайнс, 2020. - 256 с.

2. Абубакарова, Э.М., Шахгираев, И.У. Стратегический анализ как основа развития / Э.М. Абубакарова, И.У. Шахгираев // Актуальные вопросы современной экономики. - 2019. - №5. - С. 654-658

3. Лаптева, А.М., Васькова, И.К. Стратегический анализ предприятия / А.М. Лаптева, И.К. Васькова // Студенческий вестник. 2019. № 45-6 (95). С. 2021.

4. Чайникова, Л.Н. Особенности стратегического анализа на макроуровне // Практическая направленность обучения и исследований в вузе. 
материалы VII Всероссийской научно-практической конференции. под общ. ред. И. И. Скоробогатых, Н. И. Ивашковой. 2019. С. 73-76.

5. Рынок косметики и дрогери упал на 7,5\% за год [Электронный ресурс] Режим доступа : https://www.retail.ru/rbc/pressreleases/rynok-kosmetiki-i-drogeriupal-na-7-5-za-god/

(C) Л.А. Карапетян, В.А. Маняева, 2021 